those patients loosing DAS28-ESR remission over time: 58 patients lost DASESR remission at least once during the 4 follow-up visits. Surprisingly, 24\% (3 months), $36 \%$ (6 months), $24 \%$ (9 months) and $28 \%$ (12 months) of the patients still fulfilled the Boolean remission criteria. The only plausible reason for failing DAS28-ESR remission but staying in ACR/EULAR remission is an isolated elevation of the ESR, not accompanied by increased signs and symptoms of disease. Indeed all patients loosing DAS28-ESR remission but staying in ACR/EULAR Boolean remission had an elevated ESR equal or higher than $15 \mathrm{~mm}$. However, if DAS28 scores were calculated by C-reactive protein in the same patients, they all fulfilled remission criteria.

Conclusions: DAS28-ESR remission can be missed even if a patient fulfils the more stringent ACR/EULAR Boolean remission criteria. The reason for this remarkable constellation is an elevated erythrocyte sedimentation rate without any clinical symptoms. Hence, isolated elevations of erythrocyte sedimentation rate should be seen critical. These data show the limitations of individual instruments to assess remission in RA and show that interpretations of the erythrocyte sedimentation rate need to be done in the clinical context

Disclosure of Interest: None declared

DOI: 10.1136/annrheumdis-2018-eular.5521

\section{AB0253 RAPID REMISSION DURING THE FIRST YEAR IN EARLY ACTIVE RHEUMATOID ARTHRITIS IS ASSOCIATED WITH BETTER 5 YEARS STRUCTURAL DAMAGE OUTCOMES}

J. Legrand ${ }^{1}$, T. Kirchgesner ${ }^{1}$, T. Sokolova ${ }^{2}$, B. Vande Berg ${ }^{1}$, P. Durez ${ }^{2}$.

${ }^{1}$ Musculoskeletal Imaging Unit, ${ }^{2}$ Rheumatology, Cliniques universitaires Saint-Luc - Université Catholique de Louvain - Institut de Recherche Expérimentale et Clinique (IREC), Brussels, Belgium

Background: Remission is arguably the best and ultimate therapeutic goal in early rheumatoid arthritis (ERA). ERA patients who reach rapid and sustained remission are likely to retain good radiographic outcomes.

Objectives: The aim of this study was to evaluate the radiographic progression and the newly pathological joints in a Belgian ERA cohort during a 5 to 15 years follow-up and to correlate the Sharp score index with different indices of clinical remission observed during the first year.

Methods: This was a retrospective analysis of mean $(95 \% \mathrm{Cl})$ change from baseline $(B L)$ to 5 years Sharp/Van der Heijde (SVdH) scoring according to DAS28, SDAI, CDAI and ACR/EULAR Boolean remission scores for patients at Month 3, 6 and 12. Newly pathological joint defined by a SVdH score of 0 at baseline and a score greater than or equal to 1 at follow up were analysed as a secondary objective. 133 ERA patients naïve to DMARDs therapies were analysed (100 women and 33 men) with a mean age $\pm S D(49.9 \pm 13.3)$, mean DAS 28-CRP $(4.89 \pm 1.3)$, mean HAQ (1.25 \pm 0.67$)$, mean SDAI (28.4 \pm 15.5$)$, mean CDAI $(25.8 \pm 14.8)$ and mean SVdH (6 \pm 14$)$. Differences were statistically tested using t tests.

Results: ERA patients were divided in 2 groups: "Xrays Stable" if the delta of SVdH score was $<10(n=90)$ or "Xrays Progressive" if the delta of SVdH score was $>10(n=43)$. As expected, presence of ACPA and baseline erosion were significantly higher in the Xrays progressive group. No significant baseline characteristics differences were observed for DAS28-CRP, CDAI, SDAI, HAQ. smoking status, swollen joint count or CRP.\% of patients reaching DAS 28CRP, SDAI, $\mathrm{CDAl}$ and Boolean remission rates observed at 6 months were statistically significant different between groups (fig). There was no significant difference in clinical responses between subgroups of patients who developed new pathological joints and those who did not.

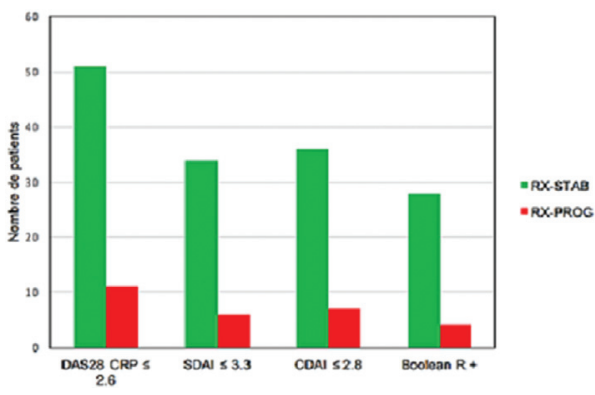

Abstract AB0253 - Figure 1

Conclusions: These results demonstrate that remission is an important therapeutic goal to protect joint damage in ERA. All remission criteria were able to predict the radiological prevention. The identification of a new pathologic joint is not associated with lack of response.
Disclosure of Interest: None declared

DOI: 10.1136/annrheumdis-2018-eular.4940

\section{AB0254 THE IMPACT OF THE PATIENT GLOBAL ASSESSMENT VARIATION ON THE DAS 28 VALUE}

K. ben abdelghani, M. boudokhane, M. chammakhi, A. fazaa, K. ouenniche,

S. kassab, S. chekili, A. laatar. Rheumatology, - Mongi Slim Hospital - La MarsaTunisia, Marsa, Tunisia

Background: Rheumatoid arthritis (RA) is the most frequent chronic inflammatory rheumatism. The DAS 28 is a disease activity measure method used to assess RA activity. It is a composite score taking into account 4 items: the number of swollen joints/28, the number of tender joints/28, the erythrocyte sedimentation rate $(E S R)$ or $C$ reactive protein (CRP) rate, the patient global assessment (PGA) indicated on a $0-10 \mathrm{~cm}$ visual analogue scale (VAS) with 'not active at all' and 'extremely active' as anchors. The DAS28 determination is very important since it guides the therapeutic decision.

Objectives: The aim of this study was to determine the different ways of asking about the PGA and to assess the impact of its value variation on the calculation of the DAS 28.

Methods: In order to determine how to evaluate the GPA, a questionnaire including 4 propositions was asked to a cohort of Tunisian rheumatologists:

1. how do you assess your health status this past week?

2. what is the degree of the disease impact in your life this last week?

3. what is the degree of the disease activity this last week?

4. other

Then, a DAS 28 calculation was proceeded according to the different choices of GPA question method for 10 Tunisian patients.

Results: The questionnaire was proposed to 37 rheumatologists, 15 working in the private sector and 22 in the public sector. These latter were 9 assistants, 3 professors, 5 specialist doctors and 5 associate professors. The first, second, third and fourth propositions were respectively chosen by 2, 14, 19 and 2 physicians. Subsequently DAS 28 was calculated. In the table 1 below, the variation of the DAS 28 value according to the choice of the PGA method is shown:

\begin{tabular}{lcccc}
\multicolumn{1}{l}{ Abstract AB0254 - Table 1 } \\
\hline Patient & $\begin{array}{c}\text { DAS 28 } \\
\text { (PGA1) }\end{array}$ & $\begin{array}{c}\text { DAS 28 } \\
\text { (PGA2) }\end{array}$ & $\begin{array}{c}\text { DAS 28 } \\
\text { (PGA3) }\end{array}$ & $\begin{array}{c}\text { DeltaDAS 28(DAS28 max- } \\
\text { min) }\end{array}$ \\
\hline 1 & 2.95 & 2.95 & 2.81 & 0.14 \\
2 & 2.53 & 2.67 & 2.67 & 0.14 \\
3 & 2.1 & 1.96 & 1.96 & 0.14 \\
4 & 5.82 & 5.82 & 5.54 & 0.28 \\
5 & 5.30 & 5.30 & 5.16 & 0.14 \\
6 & 2.87 & 2.87 & 2.87 & 0.00 \\
7 & 8.22 & 8.22 & 8.22 & 0.00 \\
8 & 4.97 & 5.11 & 5.11 & 0.14 \\
9 & 7.49 & 7.35 & 7.63 & 0.14 \\
10 & 2.03 & 2.17 & 1.89 & 0.28 \\
\hline
\end{tabular}

Conclusions: The GPA question is a subjective item taken into account for the calculation of the DAS 28. Despite the different ways of asking about it, our study showed that this factor have no real impact on the DAS28 value variation since it doesn't exceed 0.6. DAS28 remains a reliable tool in the clinical practice. Disclosure of Interest: None declared DOI: 10.1136/annrheumdis-2018-eular.5691

\section{AB0255 \\ DOES MENOPAUSE AFFECT DISEASE ACTIVITY OF RHEUMATOID ARTHRITIS(RA)? AN ANALYSIS FROM THE NINJA COHORT IN 2016}

K. Nagahata ${ }^{1}$, S. Tsuzuki ${ }^{1}$, S. Hattori ${ }^{1}$, K. Yomono $^{1}$, S. Suzuki ${ }^{1}$, S. Takenouchi ${ }^{1}$, R. Yokochi ${ }^{1}$, N. Hagino ${ }^{1}$, T. Matsui ${ }^{2}$, S. Tohma ${ }^{3} .{ }^{1}$ Division of Hematology and Rheumatology, Teikyo University Chiba Medical Center, Chiba; ${ }^{2}$ Department of Rheumatology, Clinical Research Center for Allergy and Rheumatology, National Hospital Organization Sagamihara National Hospital, Sagamihara; ${ }^{3}$ Department of Rheumatology, National Hospital Organization Tokyo National Hospital, Tokyo, Japan

Background: Early menopause may be a risk of developing $\mathrm{RA}^{1}$. Although there are many reports about menopause and the onset of RA, it is not yet clear how the disease activity of RA differs for each generation including menopause. 